\title{
Dukungan Suami Meningkatkan Kunjungan Pemeriksaan K4 Ibu Hamil
}

\author{
Eva Nurhidayati ${ }^{*}$, Emdat Suprayitno $^{2}$ \\ ${ }^{1,2}$ Fakultas Ilmu Kesehatan, Universitas Wiraraja \\ *Email: evanurhidayati06@gmail.com
}

\begin{abstract}
Background: $K 4$ is the fourth prenatal check-up visit for health workers to obtain antenatal care according to standards and to detect complications as early as possible during pregnancy. The K4 coverage in Batang-Batang Daya village, the working area of the Batang-Batang Puskesmas is still below the target in 2018. The purpose of this study was to determine the relationship between husband's support and the decision of pregnant women in carrying out K4 examinations. Methods: The design of this study is analytic correlational with a cross-sectional study approach, the population of pregnant women in the third trimester of pregnancy in Batang-Batang Daya Village in 2019 was 27 respondents, using total sampling techniques, husband's support data was collected using a valid and reliable questionnaire. K4 examination data used a checklist in the KIA book, and the statistical test used was Chi-Square with an expected value of less than 5. Result: The results showed that most of the pregnant women received support from their husbands as many as 20 people (74.1). Most of the pregnant women underwent a K4 examination (4th pregnancy visit), as many as 20 people (74.1\%). The analysis result from the Chi-Square test shows the value $(\rho)=0.000$. Conclusion: It can be concluded that the husband's support is related to the decision by pregnant women to carry out K4 examinations. Husbands should always provide support to their wives to carry out routine checks so that pregnant women are motivated to carry out K4 examinations, and are more confident about carrying out their pregnancy.
\end{abstract}

Keywords: decision, examination $k 4$, husband support

\section{PENDAHULUAN}

Masalah nasional yang memerlukan prioritas utama adalah kesehatan ibu dan bayi. Tercukupinya perhatian pada ibu hamil didalam keluarga memerlukan perhatian yang khusus dikarenakan Indonesia masih merupakan negara tertinggi dengan masalah Angka Kematian Ibu (AKI) (Chasanah, 2017). Hasil Survei Demografi Kesehatan Indonesia (SDKI) tahun 2018, dilaporkan 228 kematian ibu dari 100.000 kelahiran hidup (Kurniasih, 2020).

Target global penurunan AKI (Angka Kematian Ibu) Menurut MDG's (Millenium Development Goals) 2015 diharapankan 102 dari 100.000 adanya kelahiran hidup. Dari 1000 adanya kelahiran hidup terdapat 23 angka kematian bayi. Salah satu upaya untuk menurunkan AKI adalah dengan meningkatkan cakupan K4 (Sembiring, 2020). Berdasarkan data Propinsi Jawa Timur tahun 2018 yang dikeluarkan Dinas Kesehatan Propinsi Jawa Timur, hasil cakupan K4 yang ditetapkan masih dibawah target maksimal yaitu mencapai $84,38 \%$. Dari hasil pencatatan data Dinas Kesehatan Kabupaten Sumenep tahun 2011 cakupan K4 mencapai 82,31\%, dan ditahun 2012 didapatkan cakupan K4 sebesar 76,05\%. Hal ini tidak sesuai dengan target pencapaian K4 yang seharusnya 90\% (Fatoni, 2014). Cakupan K4 di Jawa Timur pada tahun 2018 sebesar 83,3\%, dan di Kabupaten Sumenep sebesar 90,1\%. Menurut data KIA di UPT Puskesmas Batang-Batang tahun 2017 didapatkan bahwa cakupan K4 terendah ialah desa Batang-Batang Daya yaitu $88,7 \%$ dari target $95 \%$, cakupan K4 2018 (Fatoni, 2018). 
Masalah pada penelitian ini yaitu rendahnya cakupan K4 didesa Batangbatang Daya di tahun 2018 yang mencapai $88,7 \%$ dari target yang seharusnya telah dicapai 95\%. K4 adalah kunjungan pemeriksaan kehamilan yang keempat pada tenaga kesehatan guna memperoleh pelayanan antenatal menurut standart dan bisa mendeteksi sedini mungkin adanya komplikasi pada masa kehamilan. Untuk mengontrol angka pertumbuhan penduduk dan jumlah $\mathrm{AKI}$ dan $\mathrm{AKB}$ bisa dengan melakukan cara program keluarga berencana (Indriyani \& Suprayitno, 2017). Dampak dari tidak melakukan pemeriksaan kehamilan dengan cukup rutin adalah tidak dapat mendeteksi kelainan sejak dini seperti kehamilan ganda, kelainan letak janin, kelainan pertumbuhan janin, dan penyulit pada kehamilan dan persalinan akan sering dijumpai seperti anemia, pre-eklampsi, eklampsi, ketuban pecah dini, plasenta previa, solusio plasenta, disproporsi sevalo pelvic, bayi besar, partus premature, retensio plasenta, letak lintang, lilitan tali pusat, denyut jantung janin tidak normal, IUFD, partus kala II lama, sehingga ibu hamil datang kerumah sakit dalam keadaan berat (Prawirohardjo, 2006).

Salah satu upaya untuk menurunkan angka kematian tersebut pemerintah mencanangkan making pregnancy safer dan upaya intervensi strategis dalam upaya pendekatan safer mother hood, kedua upaya tersebut sama-sama ditekankan pada pelayanan Antenatal Care (ANC) (Zulfa, 2016). Suatu perilaku seseorang dapat dipengaruhi lingkungan keluarga orang tersebut. Termotivasinya seseorang dalam berperilaku sangat erat dengan adanya dukungan dari orang terdekat sehingga ia berperilaku sesuai dengan dukungan yang telah diberikan. Sehingga dukungan yang baik dari keluarga, maka semakin baik pula seseorang untuk bersikap dan berperilaku (Suprayitno et al., 2020).

Disamping itu juga penting untuk melakukan ulasan lebih dalam serta mencari penyebab terjadi rendahnya atau menurunnya jangkauan bulanan sehingga dapat mengupayakan cara penanganan masalah secara spesifik, rendahnya cakupan kunjungan K4 pada ibu hamil dengan kehamilan trimester III dipengaruhi oleh beberapa faktor yaitu diantaranya pengetahuan, pendidikan, sikap, pekerjaan, umur, paritas, sosial ekonomi, dukungan suami, informasi, sosial budaya, tenaga kesehatan, sarana kesehatan, lingkungan serta dukungan petugas Kesehatan (Salat \& Suprayitno, 2019) ; Sugiyanto, 2013). Hasil penelitian sebelumnya menunjukan bahwa terdapat hubungan bermakna antara pendidikan ibu dengan kelengkapan pemeriksaan kehamilan sedangkan umur dan paritas tidak ada hubungan yang bermakna dengan kelengkapan pemeriksaan kehamilan (K4) (Wulandari \& Ariesta, 2015). Penelitian ini menilai usia, pendidikan, pekerjaan, dan jumlah anak, sehingga berbeda dengan penelitian lainnya. Tujuan penelitian ini adalah untuk mengetahui hubungan dukungan suami dengan pemeriksaan K4 Ibu hamil di Desa Batang-Batang.

\section{METODE PENELTIAN}

Metode penelitian yaitu analytic correlational. Semua ibu hamil trimester III di Desa Batang-Batang Daya pada bulan Mei 2019 yaitu sebanyak 27 orang merupakan populasi yang digunakan dalam studi ini. Teknik sampling penelitian ini, 
menggunakan teknik probability sampling dengan jenis total sampling. Sampel penelitian ini menggunakan semua ibu hamil trimester III di Desa Batang-Batang Daya Kecamatan BatangBatang Kabupaten Sumenep pada bulan Mei 2019 yaitu sebanyak 27 orang.

Variabel penelitian ini yaitu dukungan suami merupakan variabel independent dan variabel dependentnya adalah keputusan dari ibu hamil dalam melakukan pemeriksaan K4. Instrument penelitian yaitu check list pada buku KIA untuk mengetahui kunjungan K4 dan lembar kuesioner untuk mengetahui dukungan suami. Kuesioner ini telah dilakukan uji validitas yang menunjukkan bahwa setiap item pernyataan memiliki nilai $\mathrm{r}$ hitung antara $0,375-0,781$ dan tidak terdapat pernyataan yang tidak valid. Hasil uji reliabilitas menunjukkan bahwa semua pernyataan adalah reliabel dengan nilai reliabilitas yaitu 0,949. Data dilakukan analisis dengan menggunakan uji korelasi chi square.

\section{HASIL PENELITIAN}

\section{Data Umum}

a. Umur Ibu Hamil

Tabel 1. Distribusi Frekuensi Berdasarkan Usia Ibu Hamil di Desa Batang-Batang Daya Tahun 2019.

\begin{tabular}{ccc}
\hline Usia & \multicolumn{3}{c}{ Jumlah } \\
\cline { 2 - 3 } & Frekuensi & \% \\
\hline $12-16$ & 0 & 0 \\
$17-25$ & 8 & 29,6 \\
$26-35$ & 16 & 59,3 \\
$36-45$ & 3 & 11,1 \\
\hline Jumlah & $\mathbf{2 7}$ & $\mathbf{1 0 0}$ \\
\hline
\end{tabular}

Berdasarkan dari tabel 1 merupakan 16 orang ibu hamil yang diatas, sebagian besar $(59,3 \%)$ memiliki usia 26-35 tahun.

b. Pendidikan Ibu

Tabel 2. Distribusi Frekuensi Berdasarkan Pendidikan Ibu Hamil di Desa BatangBatang Daya Tahun 2019.

\begin{tabular}{ccc}
\hline \multirow{2}{*}{ Pendidikan } & \multicolumn{2}{c}{ Jumlah } \\
\cline { 2 - 3 } & Frekuensi & \% \\
\hline Dasar & 19 & 70,4 \\
Menengah & 5 & 18,5 \\
Tinggi & 3 & 11,1 \\
\hline Jumlah & $\mathbf{2 7}$ & $\mathbf{1 0 0}$ \\
\hline
\end{tabular}

Berdasarkan dari tabel 2 sebagian besar (70,4\%) yaitu 19 diatas, dapat disimpulkan bahwa orang ibu hamil berpendidikan dasar. 
c. Pekerjaan Ibu

Tabel 3. Distribusi Frekuensi Berdasarkan Pekerjaan Ibu Hamil di Desa BatangBatang Daya Tahun 2019.

\begin{tabular}{ccc}
\hline \multirow{2}{*}{ Pendidikan } & \multicolumn{2}{c}{ Jumlah } \\
\cline { 2 - 3 } & Frekuensi & \% \\
\hline Tidak Bekerja & 10 & 37,0 \\
Petani & 4 & 14,8 \\
Swasta & 12 & 44,5 \\
PNS & 1 & 3,7 \\
\hline Jumlah & $\mathbf{2 7}$ & $\mathbf{1 0 0}$ \\
\hline
\end{tabular}

Berdasarkan dari tabel 3, dapat disimpulkan bahwa hampir setengah

$(44,4 \%)$ yaitu 12 orang ibu hamil merupakan pekerja swasta.

d. Paritas (Jumlah anak)

Tabel 4. Distribusi Frekuensi Berdasarkan Paritas Ibu Hamil di Desa BatangBatang Daya Tahun 2019.

\begin{tabular}{ccc}
\hline \multirow{2}{*}{ Paritas } & \multicolumn{2}{c}{ Jumlah } \\
\cline { 2 - 3 } & Frekuensi & \% \\
\hline 1 Anak & 14 & 51,9 \\
2 Anak & 11 & 40,7 \\
3 Anak & 1 & 3,7 \\
> A Anak & 1 & 3,7 \\
\hline Jumlah & $\mathbf{2 7}$ & $\mathbf{1 0 0}$ \\
\hline
\end{tabular}

Berdasarkan dari tabel 4 sebagian besar (51,9\%) yaitu 14 orang diatas, dapat disimpulkan bahwa ibu hamil mempunyai 1 anak.

e. Umur Suami

Tabel 5. Distribusi Frekuensi Berdasarkan Usia Suami Ibu Hamil di Desa Batang-Batang Daya Tahun 2019.

\begin{tabular}{ccc}
\hline \multirow{2}{*}{ Usia } & \multicolumn{2}{c}{ Jumlah } \\
\cline { 2 - 3 } & Frekuensi & \% \\
\hline $12-16$ & 0 & 0 \\
$17-25$ & 3 & 11,1 \\
$26-35$ & 15 & 55,6 \\
$36-45$ & 9 & 33,3 \\
\hline Jumlah & $\mathbf{2 7}$ & $\mathbf{1 0 0}$ \\
\hline
\end{tabular}

Berdasarkan dari tabel 5 bagian besar $(55,6 \%)$ yaitu 15 orang diatas, dapat disimpulkan bahwa se- suami ibu hamil berusia 26-35 tahun. 
f. Pendidikan Suami

Tabel 6. Distribusi Frekuensi Berdasarkan Pendidikan Suami Ibu Hamil di Desa Batang-Batang Daya Tahun 2019.

\begin{tabular}{ccc}
\hline \multirow{2}{*}{ Pendidik } & \multicolumn{2}{c}{ Jumlah } \\
\cline { 2 - 3 } & Frekuensi & \% \\
\hline Dasar & 7 & 25,9 \\
Menengah & 6 & 22,2 \\
Tinggi & 14 & 51,9 \\
\hline Jumlah & $\mathbf{2 7}$ & $\mathbf{1 0 0}$ \\
\hline
\end{tabular}

Berdasarkan dari tabel 6 sebagian besar $(51,9 \%)$ yaitu 14 orang diatas, dapat disimpulkan bahwa suami ibu hamil berpendidikan Tinggi.

g. Pekerjaan Suami

Tabel 7. Distribusi Frekuensi Berdasarkan Pekerjaan Suami Ibu Hamil di Desa Batang-Batang Daya Tahun 2019.

\begin{tabular}{ccc}
\hline \multirow{2}{*}{ Pekerjaan } & \multicolumn{2}{c}{ Jumlah } \\
\cline { 2 - 3 } Tidak bekerja & Frekuensi & \% \\
Petani & 0 & 0 \\
Swasta & 10 & 37,0 \\
PNS & 15 & 55,6 \\
Jumlah & 2 & 7,4 \\
\hline
\end{tabular}

Berdasarkan tabel 7 diatas, besar $(55,6 \%)$ yaitu 15 orang suami ibu dapat disimpulkan bahwa sebagian hamil memiliki pekerjaan swasta.

h. Jumlah Anak

Tabel 8. Distribusi Frekuensi Berdasarkan Jumlah Anak Suami Ibu Hamil di Desa Batang-Batang Daya Tahun 2019.

\begin{tabular}{ccc}
\hline \multirow{2}{*}{ Jumlah Anak } & \multicolumn{2}{c}{ Jumlah } \\
\cline { 2 - 3 } & Frekuensi & \% \\
\hline 1 Anak & 14 & 51,9 \\
2 Anak & 11 & 40,7 \\
3 Anak & 1 & 3,7 \\
3 Anak & 1 & 3,7 \\
\hline Jumlah & $\mathbf{2 7}$ & $\mathbf{1 0 0 , 0}$ \\
\hline
\end{tabular}

Berdasarkan tabel 8 diatas, dapat disimpulkan bahwa sebagian besar $(51.9 \%)$ yaitu 14 orang suami ibu hamil mempunyai 1 anak. Hubungan dukungan suami dengan keputusan ibu hamil dalam melakukan pemeriksaan $\mathrm{K} 4$. 
Tabel 9. Distribusi Frekuensi Berdasarkan Keputusan Ibu Hamil Melakukan Pemeriksaan K4 di Desa Batang-Batang Daya Tahun 2019.

\begin{tabular}{lcccccc}
\hline \multirow{2}{*}{ Dukungan Suami } & \multicolumn{7}{c}{ Tidak } \\
& \multicolumn{1}{c}{ Memeriksakan K4 } & $\begin{array}{c}\text { Memeriksakan } \\
\text { K4 }\end{array}$ & Jumlah \\
\cline { 2 - 8 } & $\mathbf{N}$ & $\mathbf{\%}$ & $\mathbf{N}$ & $\mathbf{\%}$ & $\mathbf{N}$ & $\mathbf{\%}$ \\
\hline Mendukung & 19 & 9 & 1 & 5 & 20 & 100 \\
Tidak Mendukung & 1 & 1 & 6 & 8 & 7 & 100 \\
\hline \multicolumn{1}{c}{ Jumlah } & $\mathbf{2 0}$ & $\mathbf{7}$ & $\mathbf{7}$ & $\mathbf{1 3}$ & $\mathbf{2 7}$ & $\mathbf{1 0 0}$ \\
\hline & $\alpha=0,05$ & Asymp.sign $(\rho)=0,000$ \\
\hline
\end{tabular}

Tabel 9 menjelaskan bahwa dukungan suami yang didapat oleh 20 responden hampir seluruhnya $(95 \%)$ yaitu 19 ibu hamil di Desa Batang Batang Daya melakukan pemeriksaan K4. Dan tidak mendapatkan dukungan suami dari 7 responden hampir seluruhnya $(85,7 \%)$ yaitu 6 ibu hamil di Desa Batan - Batang Daya tidak melakukan pemeriksaan K4. Dari tabel diatas, kemudian dijabarkan dengan uji statistik Chi Square dengan hasil sig 0,000. Hal itu menunjukkan ada hubungan antara dukungan suami dengan keputusan ibu hamil dalam melakukan pemeriksaan K4 di Desa Batang - Batang Daya.

\section{PEMBAHASAN}

Berdasarkan penelitian di Desa Batang-Batang Daya, diketahui dari tabel 5.11 menyatakan bahwa dari 27 responden sebagian besar $(74,1 \%)$ yaitu 20 orang mendapatkan dukungan suami. Dukungan suami merupakan motivasi istri dimana suami dapat mendukung secara psikologis. Dapat berbentuk motivasi, dukungan serta penerimaan untuk melakukan kunjungan ANC. Suami sebagai bagian terpenting keluarga, maka sangat diperlukan dalam mengambil kebijakan dan keputusan dalam keluarga. Dukungan sendiri adalah factor penguat (reinforcing factor) yang bisa memberi pengaruh pada seseorang dalam bertingkah laku (Notoatmodjo, 2010).

Hasil ini sejalan dengan penelitian yang menyatakan bahwa terdapat hubungan dukungan suami dengan keteraturan antenatal care pada ibu hamil (Nabilah \& Daryanti, 2017). Hasil penelitian lainnya juga mendukung bahwa terdapat hubungan suami dengan pemeriksaan antenatal care (ANC) K1 ibu hamil (Vitriyani, 2012). Adanya dukungan dari suami, keluarga dan juga lingkungan sekitar sangat memotivasi dalam pemeriksaan ANC ibu hamil, pengaruh positif pada keadaan psikologis ibu dan bayi dapat diberikan dengan dukungan keluarga yang menerima kehamilan tersebut. Dukungan keluarga terbagi dua yaitu internal dan ekstenal. Dukungan keluarga internal adalah dukungan dari suami, saudara kandung, mertua, dan dukungan dari anak. Sedangkan dukungan eksternal adalah sahabat, pekerjaan, tetangga, dan keluarga besar (Friedman, 2005).

Berdasarkan dari hasil penelitian didapatkan bahwa sebagian besar $(55,6 \%)$ adalah 15 orang suami dari ibu hamil berusia 26-35 tahun, pada usia ini seorang suami mampu menerima informasi dan memberikan dukungan yang positif 
terhadap istri, pengalaman yang didapatkan oleh suami juga banyak, sehingga seorang suami mampu memberikan keputusan yang tepat untuk istri agar memeriksakan kehamilannya. Umur adalah indikator yang mencantumkan beberapa individu dalam urutan perkembangan (Hurlock, 2001). Menurut Notoadmodjo (2010), semakin berusia seseorang maka semakin baik juga proses perkembangan mental dan intelektualnya. Sehingga memungkinkan semakin baik dukungan yang diberikan kepada ibu hamil (Notoatmodjo, 2010).

Berdasarkan hasil penelitian didapatkan bahwa sebagian besar (51,9 $\%)$ yaitu 14 orang suami ibu hamil berpendidikan Tinggi. Tingginya pendidikan yang ditempuh suami, informasi yang semakin mudah diserap didukung dengan usia yang produktif, selain itu suami juga dapat memperoleh informasi dari media massa maupun elektronik, sehingga pemahaman suami dapat meningkat dan mengerti akan pentingnya pemeriksaan kehamilan pada ibu hamil, tanda bahaya dan komplikasi kehamilan secara dini. Hasil ini sejalan dengan penelitian yang menunjukkan bahwa terdapat hubungan bermakna antara pendidikan ibu dengan kelengkapan pemeriksaan kehamilan (K4) (Wulandari \& Ariesta, 2015).

Perihal tersebut sesuai dengan pernyataan oleh Notoatmodjo (2010), bahwasanya tingkat pendidikan seseorang mempengaruhi pada cara belajarnya. Semakin tinggi pendidikan seseorang dapat lebih mudah seseorang tersebut untuk memahami sebuah informasi. Banyaknya ilmu yang didapat merupakan hasil penyerapan dari berbagai informasi. Dengan adanya ilmu pengetahuan memungkinkan responden dalam menciptakan lebih banyak dukungan kepada istrinya. Akan tetapi perlu untuk ditekankan bahwa seseorang dengan tingkat pendidikan rendah belum berarti otoriter memiliki tingkat rendah dalam pengetahuannya karena pendidikan dapat didapat diluar sekolah atau pendidikan non formal (Notoatmodjo, 2010).

Dari hasil penelitian diperoleh bahwa sebagian besar $(55,6 \%)$ adalah 15 orang suami dari ibu hamil memiliki pekerjaan swasta. Sehingga dengan penghasilan yang cukup seorang suami akan lebih memperhatikan kesehatan istrinya dengan menganjurkan untuk melakukan pemeriksaan kehamilan secara rutin. Sedangkan suami yang berpenghasilan rendah belum memiliki kemampuan menyediakan dana untuk pemeriksaan, sehingga memungkinkan dukungan yang diberikan juga kurang maksimal, tetapi dalam hal ini dukungan suami tetap dibutuhkan agar memotivasi ibu untuk melakukan pemeriksaan kehamilan ke posyandu.

Menurut Widyaningsih (2011), pemberdayaan pada suami perlu disangkut pautkan dengan pemberdayaan ekonomi keluarga sehingga pemimpin dalam keluarga tidak beralasan dalam tidak memberi perhatian pada kesehatan istrinya. Diantaranya dukungan dari suami yang bisa diutarakan kepada istri adalah dukungan secara moneter. Perlunya memiliki suatu pekerjaan dan penghasilan dapat membantu dalam perolehan keuangan.

Berdasarkan hasil penelitian di dapatkan bahwa sebagian besar $(51,9 \%)$ yaitu 14 orang suami ibu hamil mempunyai 1 anak. Sehingga seorang suami sudah mempunyai pengalaman terhadap kehamilan istri, Dalam hal ini 
dukungan seorang suami r sangat
berharga, karena ibu hamil
menginginkan suami $\quad$ memberikan
tindakan suportif dan rasa aman, dengan
adanya dukungan suami dapat
menumbuhkan rasa percaya diri seorang
istri untuk melewati masa kehamilannya
dan melahirkan dengan selamat (Salat \&
Suprayitno, 2019).

Berdasarkan hasil penelitian didapatkan bahwa sebagian besar $(51,9 \%)$ yaitu 14 orang suami ibu hamil mempunyai kedua orang tua, Sehingga memungkinkan seorang suami untuk mendapat dukungan dari keluarga dan mengambil keputusan yang tepat memeriksakan kehamilan istrinya dengan rutin. Sikap perhatian dan kasih saying oleh suami merupakan bentuk dari dukungan suami. Dukungan tersebut bisa dapat berupa dukungan fisik ataupun psikologis. Suami mempunyai peran besar untuk meningkatkan kesehatan ibu. Memeriksakan kehamilan ibu dapat dimotivasi dengan dukungan suami (Salat \& Suprayitno, 2019).

Menurut Ivanna (2011), dukungan suami untuk pelayanan antenatal care dapat berupa kasih sayang dan perhatian untuk istrinya, memotivasi dan menemani istrinya dalam pemeriksaan kehamilan menuju fasilitas pelayanan kesehatan terdekat, melengkapi kebutuhan gizi, membantu memastikan tempat persalinan (fasilitas pelayanan kesehatan) juga menyiapkan pembiayaan biaya untuk persalinan. Dari pernyataan tersebut menunjukkan bahwa dari beberapa faktor diatas dapat mempengaruhi suami untuk memberikan dukungan terhadap istri. Seorang istri yang mendapat dukungan dari suami mempunyai kepercayaan diri dalam menjalani masa kehamilanya hingga menjalani proses persalinan.

Untuk itu diperlukan peran tenaga kesehatan dalam memberikan konseling, kepada suami agar meningkatkan pencarian informasi mencakup adanya peringatan tanda-tanda bahaya kehamilan, tanda-tanda akan terjadinya persalinan dan komplikasi yang dapat terjadi pada masa kehamilan dan persalinan, sehingga semakin banyak pengetahuan yang dimilikinya, sehingga dapat memberikan dukungan pada istri dalam menjalani masa kehamilan, dan dapat mengambil keputusan yang cepat dan tepat (Suprayitno et al., 2018).

Tabel 5. menjelaskan bahwa dari 27 responden sebagian besar $(74,1 \%)$ merupakan 20 orang yang melakukan pemeriksaan K4. Keputusan yaitu rakitan prosedur dari pemikiran yang berbentuk pemilihan salah satu diantara beberapa opsi yang dapat dipergunakan sebagai pembedah masalah yang dihadapi. Pertimbangan diambil untuk dilaksanakan dalam rangka pencapaian suatu tujuan yang telah ditentukan (Kurnia, 2015). Faktor-faktor yang dapat mempengaruhi pengambilan suatu keputusan yaitu faktor internal dan faktor eksternal, dimana faktor internal diantaranya : kondisi emosional dan fisik, individual karakteristik, kebudayaan, sosial, latar belakang filosofi, pengalaman masa lalu, ketertarikan, pengetahuan dan sikap pengambilan kesimpulan yang dimiliki. Sedangkan faktor eksternal yaitu keadaan dan lingkungan, serta waktu. Nilai yang berdampak pada semua aspek dalam pengambilan ketetapan yaitu pernyataan masalah, dan bagaimana pertimbangan itu dapat dicapai. Nilai dapat ditetapkan dengan salah satu kebudayaan, sosial, latar belakang, 
filosofi social dan budaya (Wulandari \& Ariesta, 2015).

Kunjungan ibu hamil merupakan tatap muka ibu hamil dengan petugas kesehatan yang menyediakan pelayanan antenatal untuk memperoleh pemeriksaan pada kehamilan. Pengelolaan antenatal menyediakan manfaat dengan dijumpainya abnormalitas yang dapat menyertai kehamilan sedini mungkin sehingga dapat memprediksikan dan membekali langkah- langkah pertolongan dalam persalinannya (Suprayitno et al., 2018). Kunjungan K-4 yaitu relasi ibu hamil keempat atau lebih dengan petugas kesehatan untuk menerima pemeriksaan kehamilan, dengan penyaluran kontak sebagai berikut : sekurang-kurangnya 1 kali pada triwulan pertama, sekurangkurangnya 1 kali pada triwulan kedua, dan sedikitnya 2 kali pada triwulan ketiga (Depkes RI, 2005).

Berlandaskan hasil penelitian diperoleh sebagian besar (59,3\%) merupakan 16 orang ibu hamil yang berumur 26-35 tahun. Menurut Singgih (1998), yang telah dikutip dari Hendra (2012), bahwa proses peningkatan mental yang semakin baik bertambah seiring tuanya usia seseorang, akan tetapi peningkatan proses perkembangan mental ini tidak bisa sepesat seperti ketika usianya belasan tahun pada umur tertentu. Pada usia tersebut seseorang akan cakap dalam menampung informasi dengan cukup baik, sehingga ibu yang berusia produktif akan lebih berpikir secara masuk akal dan mantap tentang berartinya melakukan pemeriksaan K4 dalam masa kehamilan.

Berdasarkan dari hasil penelitian diketahui bahwa sebagian besar $(70,4 \%)$ merupakan 19 orang ibu hamil dengan pendidikan Dasar. Pengertian pendidikan yaitu suatu proses pembelajaran pengetahuan, kemampuan serta keterampilan yang dilihat dari kebiasaan setiap orang, yang menjadi bahan warisan dari orang sebelumnya hingga sekarang.

Pendidikan sangat dekat hubungannya dengan kemampuan mengetahui sesuatu. Dikarenakan Pendidikan adalah salah satu kegiatan formal untuk mendapatkan ilmu pengetahuan (Suprayitno et al., 2018). Semakin tingginya derajat pendidikan seseorang maka semakin logis ia dalam menentukan suatu keputusan, derajat pendidikan berdampak pada kesadaran terhadap pentingnya kesehatan, kebanyakan ibu hamil yang berpendidikan dasar tidak cakap dalam mengambil keputusannya sendiri, masih bergantung kepada orang yang lebih mahir khususnya suami (Indriyani et al., 2020).

Berdasarkan dari hasil penelitian didapatkan bahwa hampir setengah $(44,5 \%)$ merupakan 12 orang ibu hamil yang memiliki pekerjaan swasta. Perempuan yang bekerja akan lebih menguntungkan pelayanan antenatal care dibandingkan dengan perempuan sebagai ibu rumah tangga dan yang tidak berprofesi,.Seseorang yang menyandang pekerjaan dengan berita lebih luas terdapat kemiringan berpengetahuan yang lebih baik, dan pengalaman yang luas, sehingga informasi yang diperoleh lebih banyak mengenai faedah dan kemudaratan melakukan pemeriksaan kehamilan, hal itu sangat mempengaruhi ibu hamil dalam melangsungkan pemeriksaan K4 (Sugiyanto, 2013).

Berdasarkan hasil penelitian didapatkan bahwa sebagian besar $(51,9 \%)$ yaitu 14 orang ibu hamil mempunyai seorang anak, dan melakukan 
pemeriksaan kehamilan, hal ini dimungkinkan dapat dipengaruhi oleh pengalaman ibu hamil terdahulu, sehingga mereka ingin lebih baik dalam menjaga kehamilannya dan mempersiapkan persalinannya (Komariyah, 2009). Berdasarkan hasil penelitian didapatkan bahwa sebagian besar $(63 \%)$ yaitu 17 orang ibu hamil mempunyai kedua orang tua. Kuatnya keinginan ibu untuk melakukan yang terbaik untuk kesehatan kehamilannya bergantung dengan kuatnya dorongan dan dukungan dari keluarga terdekatnya. Timbulnya kebiasaan yang baik pada ibu karena adanya dorongan yang baik pula, sehingga ingin melakukan pemeriksaan kehamilan secara rutin (Wulandari \& Ariesta, 2015).

Dapat diketahui bahwa untuk mengambil keputusan seorang istri masih bergantung pada suami, ketika suam memberikan dukungan kepada istri, maka seorang istri tidak merasa ragu lagi dalam mengambil suatu keputusan, dengan adanya dukungan suami dalam masa kehamilan, seorang istri akan termotivasi untuk menjaga kehamilannya dengan baik dan melakukan pemeriksaan kehamilan untuk mengetahui pertumbuhan dan perkembangan janinnya sampai akhir masa kehamilannya. Sehingga ibu dapat mendeteksi secara dini bahaya kehamilan, tanda persalinan dan cara penanganan awal masalah kehamilan (Salat \& Suprayitno, 2019).

Upaya yang dapat dia lakukan diantaranya dengan penyuluhan, salah satunya member penyuluhan terhadap ibu hamil tentang pentingnya melakukan ANC, memberikan informasi tentang kesehatan yang berhubungan dengan kesehatan ibu hamil, seperti waktu melakukan pemeriksaan ANC, dampak apabila tidak melakukan ANC dan keuntungan melakukan ANC yang rutin, dengan sosialisasi dan melakukan ANC diharapkan dapat dideteksi secara dini keadaan yang mengandung resiko kehamilan baik bagi ibu maupun janin (Kurnia, 2015). Berdasarkan tabel 9 menunjukkan bahwa, dari 20 responden yang mendapatkan dukungan suami hampir seluruhnya (95\%) yaitu $19 \mathrm{ibu}$ hamil di Desa Batang-Batang Daya melakukan pemeriksaan K4. Dan dari 7 responden yang tidak menerima dukungan suami hampir seluruhnya $(85,7 \%)$ yaitu 6 ibu hamil di Desa Batang-Batang Daya tidak melakukan pemeriksaan K4.

Hasil dari uji statistik Chi Square. Ditemukan bahwa nilai sig 0,000 dengan derajat kemaknaan 0,05 sehingga kurang dari $\alpha(\mathrm{P}<\alpha)$. Hal tersebut mengacu pada adanya jalinan antara dukungan suami dengan keputusan oleh ibu hamil dalam melaksanakan pemeriksaan K4 di Desa Batang-Batang Daya Kecamatan BatangBatang Kabupaten Sumenep. Menurut Prianggoro (2012), bahwa dengan mendampingi istri saat melakukan pemeriksaan, suami akan lebih banyak dalam menerima berita sehingga lebih siap untuk menghadapi kehamilan dan juga persalinan istrinya. Selain itu istri juga akan lebih merasa tenang dan senang saat diperiksa apabila didampingi oleh suaminya (Sulistyowati, 2012).

Ada beberapa aspek yang cukup berfungsi dalam eskalasi kapasitas wanita untuk penyesuaian terhadap kehamilannya, misalnya lingkungan sosial, dukungan sosial dan dukungan dari pemberi asuhan termasuk tenaga kesehatannya. Dukungan yang diberikan suami dan keluarga bisa mempengaruhi dalam keinginan melakukan pemeriksaan kehamilan, persepsi yang dimiliki ibu 
terhadap kehamilan dan berdampak pada tingkat kecemasan serta mekanisme koping yang ibu alami (Salat \& Suprayitno, 2019).

Hal tersebut didukung oleh studi yang telah dilakukan oleh Lia Mulyanti (2010) hasil uraian univariat untuk variable dukungan suami diperoleh : responden yang tidak menerima dukungan suami ada 17 orang $(56,7 \%)$ sedangkan responden yang menerima dukungan suami ada 13 orang (43,3\%). Sedangkan kunjungan ANC : 17 orang $(56,7 \%)$ telah melakukan kunjungan ANC dengan baik dan 13 orang (43,3\%) melakukan kunjungan ANC dengan tidak baik. Dari Chi square test diperoleh $\mathrm{p}=0,007$. Oleh karena nilai $\mathrm{p}<0,05$; maka dapat diambil determinasi yaitu terdapat suatu ikatan antara dukungan dari suami pada ibu hamil dengan kunjungan ANC (Mulyanti, 2013). Pernyataan Sulistyorini (2007) bahwa tersedianya dukungan dan peran serta dari suami pada saat masa kehamilan terbukti dapat meningkatkan tingkat kesiapan ibu hamil dalam menempuh masa kehamilan dan proses persalinan nanti (Aprianawati \& Sulistyorini, 2007).

Upaya yang dapat dilakukan untuk meningkatkan dukungan dari suami terhadap pemeriksaan $\mathrm{K} 4$ yaitu dengan konseling tenaga kesehatan kepada suami dari pemeriksaan kehamilan pertama, tentang pentingnya melakukan pemeriksaan kehamilan dengan teratur minimal 4 kali selama masa kehamilan, kerugian dan keuntungan melakukan pemeriksaan kehamilan, mengetahui secara awal adanya tanda bahaya dan masalah yang mungkin berlangsung selama masa kehamilan, sehingga pertumbuhan dan perkembangan janin bisa terjaga dengan cukup baik sampai dengan akhir masa kehamilan, serta dapat merencanakan bagaimana proses persalinan yang aman dan nyaman (Wulandari \& Ariesta, 2015). Dengan adanya dukungan suami cakupan K4 dapat tercapai, sehingga perencanaan persalinan di tenaga kesehatan yang nantinya pertolongan persalinan dapat berjalan dengan lancar, ibu dan bayi sehat yang akan berdampak pada penurunan $\mathrm{AKI}$ dan $\mathrm{AKB}$.

\section{KESIMPULAN DAN SARAN}

Ada hubungan antara Dukungan Suami dengan Keputusan Ibu Hamil dalam melakukan pemeriksaan $\mathrm{K} 4 \mathrm{di}$ Desa Batang-Batang Daya Wilayah Kerja UPT Puskesmas Batang - Batang Kabupaten Sumenep 2019. Bagi peneliti selanjutnya perlu di cermati aspek-aspek lain yang dapat mempengaruhi ibu hamil dalam melaksanakan pemeriksaan K4, misalnya aspek sosial budaya, tenaga kesehatan, support dari petugas kesehatan, sarana dan prasarana kesehatan, serta faktor lingkungan. Bagi responden diharapkan agar suami mencari informasi tentang pentingnya melakukan pemeriksaan kehamilan dan mengetahui tanda-tanda bahaya kehamilan. Kepada ibu hamil diharapkan melakukan pemeriksaan kehamilan minimal 4x selama masa kehamilan untuk mengetahui pertumbuhan dan perkembangan janin, serta mendeteksi dini adanya kelainan selama masa kehamilanya.

\section{DAFTAR RUJUKAN}

Aprianawati, R. B., \& Sulistyorini, I. R. (2007). Hubungan antara dukungan keluarga dengan kecemasan ibu hamil menghadapi kelahiran anak pertama pada masa triwulan ketiga. 
Yogyakarta: Universitas Gajah Mada.

Chasanah, S. U. (2017). Peran Petugas Kesehatan Masyarakat dalam Upaya Penurunan Angka Kematian Ibu Pasca MDGs 2015. Jurnal Kesehatan Masyarakat Andalas, 9(2), 73-79. https://doi.org/I: https://doi.org/10.24893/jkma.v9i2.1 90

Fatoni. (2014). Profil Kesehatan Thaun 2014 Kabupaten Sumenep. http://dinkessumenep.org/sakip/Profil Kesehatan Kab Sumenep Tahun 2014.pdf

Fatoni. (2018). Profil Kesehatan Tahun 2018 Kabupaten Sumenep. https://docplayer.info/125397205Profil-kesehatan-kabupatensumenep-tahun-2017.html

Hurlock, E. B. (2001). Developmental psychology. Tata McGraw-Hill Education.

Indriyani, R., Aulia, A., Andrian, M. W., \& Suprayitno, E. (2020). Pengaruh Konsumsi Sari Buah Jambu Merah dan Madu terhadap Kenaikan Nilai HB pada Ibu Hamil di Tempat Praktek Mandiri Bidan Muarofah Surabaya. Wiraraja Medika, 10(1), 36-40.

https://doi.org/https://doi.org/10.2492 9/fik.v10i1.938

Indriyani, R., \& Suprayitno, E. (2017). Hubungan Postpartum Blues Dengan Keputusan Menggunakan KB Pasca Nifas Di UPT Puskesmas Lenteng. Journal Of Health Science (Jurnal
Ilmu Kesehatan), 2(2), 70-75. https://doi.org/https://doi.org/10.2492 9/jik.v2i2.552

Komariyah, S. (2009). Hubungan pengetahuan, sikap dan perilaku ibu hamil tentang pemeriksaan kehamilan dengan kunjungan pemeriksaan kehamilan di wilayah kerja PUSKESMAS Sukorame Mojoroto Kediri. UNS (Sebelas Maret University).

Kurnia, N. (2015). Analisis Keputusan Ibu Hamil dalam Memilih Pelayanan Antenatal Care di Wilayah Kerja Puskesmas Jambula Kota Ternat. JIKMU, 5(6).

Kurniasih, E. (2020). Hubungan tingkat pengetahuan ibu hamil trimester iii tentang tanda bahaya kehamilan dengan kepatuhan ante natal care (anc) di puskesmas geneng kabupaten ngawi. Warta bhakti husada mulia, 7(1).

Mulyanti, L. (2013). Hubungan Dukungan Suami Pada Ibu Hamil Dengan Kunjungan ANC Di Rumah Bersalin Bhakti IBI Jl. Sendangguwo Baru V No 44c Kota Semarang. Jurnal Kebidanan, 2(1).

Nabilah, F., \& Daryanti, M. S. (2017). Hubungan Dukungan Suami Dengan Keteraturan Antenatal Care (Anc) Pada Ibu Hamil Trimester Iii Di Bpm Istri Utami Sleman Yogyakarta. Universitas' Aisyiyah Yogyakarta.

Notoatmodjo, S. (2010). Ilmu Perilaku Kesehatan, Penerbit Rineka Cipta. Jakarta. 
Prawirohardjo, S. (2006). Anatomi Alat Reproduksi dan Perdarahan Pasca Persalinan. Ilmu Kebidanan. Yayasan Bina Pustaka Sarwono Prawirohardjo: Jakarta. Hal.

Salat, S. Y. S., \& Suprayitno, E. (2019). Hubungan Kecemasan Ibu Menyusui Dengan Kelancaran Pengeluaran Air Susu Ibu (Asi ) Di Bps Kerta Timur Kecamatan Dasuk Kabupaten Sumenep. Relationship Between Mother's Anxiety Analysis With The Swiftness of Breast Milk In BPS Kerta Timur Kecamatan Dasuk Kab, 5(2), 51-56. https://doi.org/https://doi.org/10.3302 3/jikeb.v5i2.479

Sembiring, R. (2020). Hubungan pengetahuan dan sikap ibu hamil tentang manfaat mengkonsumsi zat besi di desa garingging tahun 2019 . Chmk health journal, 4(2), 183-189.

Sugiyanto, S. (2013). Hubungan Dukungan Suami dengan Kelengkapan Kunjungan ANC pada Ibu Hamil TM III di Puskesmas Jetis II Bantul Tahun 2013. STIKES'Aisyiyah Yogyakarta.

Sulistyowati, F. S. (2012). Hubungan antara Dukungan Suami dengan Tingkat Kecemasan Primigravida dalam Menghadapi Trimester Tiga di RSUD Kota Surakarta.

Suprayitno, E., Pratiwi, I. G. D., \& Yasin, Z. (2018). Gambaran Penyebab Terjadinya Pembengkakan Payudara Pada Ibu Menyusui Di Polindes Desa Meddelen Kecamatan Lenteng. WIRARAJA MEDIKA, 8(1), 13-18. https://doi.org/https://doi.org/10.2492 9/fik.v8i1.505

Suprayitno, E., Purnomo, J. D. T., Sutikno, S., \& Indriyani, R. (2020). Health education in principle of community affected teenagaer's smooking attitude and habitual in the coastal area of madura island indonesia. International Journal of Psychosocial Rehabilitation, 24(10), 1492-1502.

https://doi.org/10.37200/IJPR/V24I1 0/PR300173

Vitriyani, E. (2012). Faktor-Faktor Yang Berhubungan Dengan Pemeriksaan Antenatal Care (ANC) Kl Ibu Hamil Di Kecamatan Polokarto Kabupaten Sukoharjo. Universitas Muhammadiyah Surakarta.

Wulandari, E. C., \& Ariesta, R. (2015). Hubungan Pendidikan dan Umur Ibu Hamil Dengan Kelengkapan Pemeriksaan Kehamilan (K4). Jurnal Obstretika Scientia, 2(2), 159-178.

Zulfa, F. I. (2016). Asuhan Kebidanan Ibu Nifas pada Ny. N Post Operasi Sectio Cesaria di RSUD DR. H. Suwondo Kendal Tahun 2016 (pp. 1-6). Fakultas Kedokteran UNISSULA. 